\title{
Routine Mobile Applications for Emergency Medical Services in Mass Casualty Incidents
}

\author{
T. Mentler, M. Herczeg, S. Jent, M. Stoislow \\ Institute for Multimedia and Interactive Systems (IMIS) \\ University of Lübeck, Lübeck, Germany \\ \{mentler|herczeg|jent|stoislow\}@imis.uni-luebeck.de
}

\author{
M. C. Kindsmüller \\ mck@informatik.uni-hamburg.de \\ T. Rumland, DIGITALYS GmbH, Schiffdorf, Germany \\ timo.rumland@digitalys.de
}

HCI Group, Department of Informatics, Universität Hamburg, Germany

Structure: 1. Introduction / 2. Care \& Prepare / 3. The Usability Challenge / 4. The Proposed System /

\section{Abstract}

Emergency medical services (EMS) provide pre-hospital medical care and represent an important part of the rescue chain. The paramedic and physician's work is characterized by regular day-to-day services as well as extraordinary missions within mass casualty incidents (MCIs). For several reasons, accessing, recording and communicating operational data are important tasks in any scenario of urgent medical care. Supporting an immediate and careful execution with the help of mobile technologies is accompanied by various challenges. While the mere technological problems, e.g. steady network connectivity or sufficient battery service life, are on the way of being solved within the near future, questions of usability remain. In this paper, we propose a single device solution for information, documentation and communication needs and describe our approach to ensure usability both in daily routine as well as in exceptional circumstances.

\section{Introduction}

Despite differences in exact wordings and regulation, an emergency medical services (EMS) can been generally viewed as "[...] the ambulance services component that responds to the scene of a medical or surgical emergency, stabilizes the victim of a sudden illness or injury by providing emergency medical treatment at the scene and transports the patient to a medical facility for definitive treatment" [1]. Recording and communicating operational data are important tasks both for several reasons, among them:

- Further treatment of patients in medical facilities is mainly based and depending on recorded original conditions, initial diagnosis and previously undertaken actions.

- Communication, coordination and cooperation needs can only be met successfully, if the situation is assessed correctly on the basis of comprehensive documentation.

- Incident reports are the legal basis in the event of controversies at a later date and therefore act as evidence for paramedics and emergency physicians.

- Incidents reports are the source for accounting, statistics, quality management, and other concerns.
Even in highly developed countries, most EMS still rely on paper to handle these tasks. Pervasive computer-based solutions are introduced gradually into day-to-day services but as an informal survey on the leading European professional fairs "Interschutz 2010" and "RETTmobil 2011" revealed, most stakeholders feel confident that it will take months, if not years until a paperless workflow from patient to accounting is the rule rather than the exception [2]. Nowadays, various forms, tables and tags are used and carbon copies are the tools and aids for distributing data.

Projects like AID-N, ALARM, eTriage, SpeedUp, WIISARD or WISTA deal with several questions according to Mass Casualty Incidents (MCIs) but widely disregard daily job routine of EMS [3], [4], [5], [6], [7]. Few and far between, conclusions are drawn that "technologies must be used every day, if they are to be successfully used in a critical situation" [8] and this is why one has to "match the system with current practice: Integrate systems in non-disruptive ways to promote use during routine ambulance runs" [9].

Issues of usability and user interface design emerging from these claims have not been elaborated. Until today, there is no research project we know of, considering EMS systems at large. Our following approach is trying to cope with these issues. 


\section{Care \& Prepare}

EMS are a challenging field of application. Analyzing users' needs and working contexts is complicated by various national, regional and even local organizations and regulations. While prototypical test runs are difficult ethically as well as legally, simulations or laboratory studies especially of mass casualty incidents (MCIs) have to be questioned in respect to transferability of results into real world situations. To meet these challenges in a more appropriate way, we propose the Care $\&$ Prepare approach. As the name reveals, it is based on two basic principles [2]:

- Care: An application system for managing MCIs and its user interface in particular have to be designed in consideration of the users' contexts (physical, mental, temporal). Such a system has to be tailored to meet the constraints as well as the strengths of the human cognitive-perceptive system in these particular situational conditions.

- Prepare: The cornerstone of handling an MCI successfully is to be prepared. Highly trained routine behavior is formed in day-to-day practice of paramedics and emergency physicians. A system for handling MCIs therefore has to be a "natural" extension of a mobile data gathering system for regular rescue und transport missions.

This approach takes into account that MCIs are rare events in terms of a specific EMS and an individual employee. It does not contradict the statement that the difference between MCI and daily job routine "is one of kind rather than degree" [10]. While treatment strategies, organizational structures and courses of action obviously have to differ, utilizing technical expertise seems to be desirable. Routine usage can only be derived from intense and regular application [11]. Furthermore, regular operations can turn into MCIs anytime and anywhere, e.g. a minor car accident can result in a pile-up of cars.

We conducted a survey among the leads of German EMSs. All measures were taken on 5-point Likert scales:

$\begin{array}{ll}\text { - } & \text { fully agree (2), } \\ \text { - } & \text { rather agree (1), } \\ \text { - } & \text { undecided (0), } \\ \text { - } & \text { rather disagree }(-1), \\ \text { - } & \text { fully disagree }(-2) .\end{array}$

Preliminary results show that the average of all responders rather agreed $(x=1.1)$ with the statement "Mobile electronic data gathering should be applicable both in regular operations and mass casualty incidents". And the average of all responders disagreed $(x=-1.6)$ with the statement " $A$ system which is exclusively usable in mass casualty incidents or major catastrophic events makes sense".
Taking into account that "from the point of view of the user, the interface is the system" [12], the usability of the user interface is of vital importance for suitability and acceptance of mobile computer-based documentation and information systems for EMSs.

\section{The Usability Challenge}

The challenge is to design a system that is suitable for supporting users in both situations - from a huge variety of complex situations in regular day-to-day services as well as in all task areas of MCIs: tactics, triage, treatment, take care, and transport.

\subsection{Regular day-to-day services}

Regular operations are coordinated by a regional publicsafety answering point and involve as a rule less than three units each consisting of two EMS employees. They can be divided into acute medical care and medical transport operations [13]. While the former are time-critical and have to be accomplished as fast as possible, the latter can as a rule be scheduled over a longer period.

The diversity of patients in terms of age, handicap, religion, and the wide range of injuries and diseases make it harder to get routine even in day-to-day-services. In addition, there are no restrictions concerning daytime or location of accident. Hence, serious situations can be complicated by darkness, rain or narrow spaces [14]. Nevertheless, team work and division can be practiced repeatedly and are regulated by law. Furthermore, communication, cooperation and coordination needs are arranged and guided by the public-safety answering point staff.

A video-based error analysis of emergency mission documentation in simulated care revealed that there is room for improvement according to documentation quality in German EMS. 28 teams participated in two scenarios (myocardial infarction and major trauma). They recorded drug dosages and 20 respectively 16 parameters and actions. In the major trauma scenario 138 medications were administered. 31 of them were documented incorrectly. For the STEMI scenario 469 actions were carried out. 104 of them were not documented at all. Besides training of EMS staff and quality management programs, electronic documentation is named as one possible solution [15].

\subsection{Mass Casualty Incidents}

According to [16], a mass casualty incident (MCI) can be defined as "an event, which generates more patients at one time than locally available resources can manage using routine procedures. It therefore requires exceptional emergency arrangements and additional or extraordinary assistance." Due to a shortage of rescuers, the large number of patients involved in a MCI cannot be treated like in individual emergencies. Corresponding standards of treatment are often too time-consuming and resource-intense. They could only be maintained in favor of few respectively 
to the disadvantage of many casualties. Anamnesis and diagnosis have to be made as compact and fast as possible.

What matters is a complete and comprehensible documentation of all medical actions and any other available data. A steady flow of information between the different sections and the incident command is crucial for correct assessments and for preventing chaotic situations. For instance, the flow of information between assembly and operation area turns out to be difficult. The absence of continuous communication can impinge on waiting crew members. If they are not enabled to estimate the following mission, motivation problems or anxiety states could abate abilities and performances [17].

Communication, coordination and cooperation needs on site as well as with public-safety answering point and crisis teams are met by a complex mix of one-to-one talks, radio calls, mobile phone talks and messengers. Data is manually copied and gathered from individual triage tags. Legibility and slips of the pen are just two of many thinkable sources of error. Studies point out several problems, which occur and recur, associated with simulated or real mass casualty incidents - communication and documentation being some of them [17] [18].

\subsection{Implications}

It is easily noticeable that the situations described in section 3.1 and in section 3.2 are exceedingly diverse and call for very different measures of support. Considering this diversity in situations it might not come as a surprise that up to now separate systems for each of these situations have been developed. Sophisticated and flexible documentation systems for regular day-to-day services on the one hand and experimental research systems for MCIs on the other hand.

The systems developed in projects like AID-N, ALARM, eTriage, SpeedUp, WIISARD or WISTA can be identified as results of a design approach for walk-up-and-use systems. This approach is clearly suitable for designing ATMs or ticket machines for a large and unspecified group of users. It might have been inspired by the idea of supporting users in unfamiliar situations as it is the case for almost all EMS employees in the event of an MCI. Nevertheless the users in both situations are basically the same.

In the case of EMS employees we have - in contrast of designing a walk-up-and-use system for an unspecified group of users - the advantage of being able to tailor a system to the very needs of a particular well trained group of expert users. One can and should make use of the expertise that EMS employees have built up over years of regular day-today services.

\section{The Proposed System}

A user interface includes hardware and software components which are mutually dependent in terms of input and output modalities as well as the overall interaction design.

\subsection{Hardware}

There are different hardware-related approaches to mobile data gathering in EMS. While digital respectively interactive paper offers a familiar user interface, it has several disadvantages, e.g. no on the fly input verification. Tablet PCs combine advantages of laptops and PDAs/smartphones and can further be distinguished by input and control possibilities. Pen-based interaction offers certain advantages compared to touch-based one. For example, difficulties arising from wearing gloves or dirty hands are ruled out. Other input methods supported by modern tablet PCs with built-in cameras, microphones or multi-touch support have to be judged critically. Particularly speech or gesture controls are problematic for various reasons. For example, speech input systems usually require comparatively high working memory resources of the users. These are crucial resources, which are highly needed for problem solving efforts [19]. In addition, MCIs as well as regular mission are often associated with a high noise level which could drastically decrease voice recognition rates. All in all, a rugged tablet $\mathrm{PC}$ with an exclusively pen-enabled interface can be considered as an appropriate single device solution for EMS.

\subsection{Interaction Design}

In safety- and time-critical application contexts offering a choice of possible proper input values should be preferred to free data entry, as long as the value range can be limited. Traditional desktop applications make use of check boxes, radio buttons and regular buttons in order to offer direct selection possibilities. With respect to pen-based interaction and challenges like occlusion, wizards should offer a large pointing target area. Therefore, regular buttons fit better than check boxes or radio buttons. At the same width of the component, they offer the largest event space and avoid further uncertainty as to whether the label is a target area, too. By implementing button groups, logical operations, like unselecting a button when another one gets selected, can be realized too. Apart from buttons, controls are needed which allow efficient access to a larger number of items without increasing the number of concurrently and constantly visual components disproportionately. Menu structures can be suitable on both counts.

\subsection{Implementation}

An advanced prototypical application system for managing MCIs is an on-going development in our research group and has already been reviewed and formatively evaluated by experts of different German EMSs. The goal of our project is to integrate a prototypical module into the existing 
R2-System, an end-to-end solution for regular rescue and transport missions, of the DIGITALYS GmbH.

\section{Conclusions}

Based on the Care \& Prepare approach, daily routine and extraordinary missions of EMS should be considered as two ends of a continuum within a single support system. Usability challenges arise from their different natures. Reference [20] illustrates that there are many technical possibilities managing MCIs only. With regard to the Care \& Prepare approach and usability issues, some of them (e.g. PDAs) can be ruled out. A first study we conducted as well as reviews of the prototypical implementation point out that the basic ideas of Care \& Prepare are approved by experts. Nevertheless, further research and development is necessary in order to find the right balance between technically feasible and efficiently usable.

\section{Acknowledgment}

The research leading to these results has received funding from Innovationsstiftung Schleswig Holstein, Behra Unternehmensberatung $\mathrm{GmbH}$ and University of Lübeck.

\section{$7 \quad$ References}

[1] World Health Organization: Emergency Medical Services Systems in the European Union. Avail-

ble:http://www.euro.who.int/__data/assets/pdf_file/0003/ 114564/E92039.pdf (2012, Jun. 18)

[2] Kindsmüller, M. C.; Mentler, T.; Herczeg, M.; and Rumland, T.: "Care \& Prepare - Usability Engineering for Mass Casualty Incidents" in Proceedings of the 1st International Workshop on Engineering Interactive Computing Systems for Medicine and Health Care. Co-located with the ACM SIGCHI Symposium on Engineering Interactive Computing System (EICS 2011), A. Blandford; G. De Pietro; A. Gimblett; P. Oladimeji; H. Thimbleby, Eds, 2011, pp. 30-35.

[3] Sauer, S.: SpeedUp. Available: http://www.speedupprojekt.de/speedup_multimedia/dokumente/Brosch $\% \mathrm{C} 3 \%$ BCre+SpeedUp.pdf (2012, Jun. 18)

[4] Wirth, C.; Roscher, D.; Zernicke, P.; Schultz, M.; and Carius-Düssel, C.: "Architekturentwurf für ein prozessunterstützendes Softwaresystem für den Rettungsdiensteinsatz bei einem Massenanfall von Verletzen" in Software Engineering 2010:Workshopband; Fachtagung des GI-FB Softwaretechnik, G. Engels, Ed, Bonn: Ges. für Informatik (GI), 2010, pp. 397-404.

[5] Lenert, L. A.; Chan, T. C.; Kirsh, D.; and Griswold, W. G.: Wireless Internet Information System for Medical Response in Disasters (WIISARD) Final Report. Available:http://collab.nlm.nih.gov/webcastsandvideos/siirsv/uc sdsummaryreport.pdf (2012, Jun. 18).

[6] Chu, Y.; and Ganz, A.: "WISTA: a wireless telemedicine system for disaster patient care", Mob. Netw. Appl, vol. 12, pp. 201-214, 2007.
[7] Mulero Chaves, J.; Donner, A.; Tang, C.; Adler, Ch.; Krüsmann, M.; Via Estrem, A.; and Greiner-Mai, Th.: "An interdisciplinary approach to designing a mass casualty incident management system" in Proceedings International Workshop on Emergency Telecommunications (EMT 2011 (WPMC 2011 Workshop)), Brest, France, 2011, pp. 662-666.

[8] White, D.: Advanced Health and Disaster Aid Network: Final Report. Available: http://www.jhuapl.edu/ AID-N/Pub/AID-N_Final_Report_v_0_7_091807.pdf (2012, Jun. 18).

[9] Gao, T.; Massey, T.; Sarrafzadeh, M.; Selavo, L.; and Welsh, M.: "Participatory user centered design techniques for a large scale ad-hoc health information system" in Proceedings of the 1st ACM SIGMOBILE International Workshop on Systems and Networking Support for Healthcare and Assisted Living Environments. New York, N.Y: ACM Press, 2007.

[10] Quarantelli, E. L.: Needed Innovation In Emergency Medical Services In Disasters Of The Future. Available: http://dspace.udel.edu:8080/dspace/handle/19716/471.pdf (2012, Jun. 18).

[11] Herczeg, M: Software-Ergonomie: Theorien, Modelle und Kriterien für gebrauchstaugliche interaktive Computersysteme. München: Oldenbourg, 2009.

[12] Norman, D. A.: “Cognitive Engineering," in User centered system design: New perspectives on humancomputer interaction, D. A. Norman and S. W. Draper, Eds., Hillsdale, N.J: Erlbaum, 1986, pp. 31-61.

[13] Bertschat, F.; Moller, J.; and Zander, J.: Lehrbuch für den Rettungsdienst. Berlin: Walter de Gruyter, 1999.

[14] Kühn, D.; Luxem, J.; and Runggaldier, K.: Rettungsdienst heute. München: Elsevier Urban \& Fischer, 2010.

[15] Bergrath, S.; Rörtgen, D.; Skorning, M.; Fischermann, H.; Beckers, S.; Mutscher, C.; Brokmann, J.; and Rossaint, J.: Notärztliche Einsatzdokumentation in der Simulation. Der Anaesthesist, 60, pp. 221-229, 2011

[16] World Health Organization: Mass casualty management systems. Strategies and guidelines for building health sector capacity. Available: http://www.who.int /hac/techguidance/MCM_guidelines_inside_final.pdf (2012, Jun. 18).

[17] Luiz, T.: Medizinische Gefahrenabwehr: Katastrophenmedizin und Krisenmanagement im Bevölkerungsschutz. München: Elsevier Urban \& Fischer, 2010.

[18] Scholz, J.; Sefrin, P.; Böttiger, B. W.; Dörges, V.; and Wenzel, V.: Notfallmedizin. Stuttgart: Thieme, 2007. [19] Shneiderman, B.: "The limits of speech recognition", Commun. ACM, vol. 43, pp. 63-65, 2000.

[20] Nestler, S.: Konzeption, Implementierung und Evaluierung von Benutzerschnittstellen für lebensbedrohliche, zeitkritische und instabile Situationen. Münster: Verl.Haus Monsenstein und Vannerdat, 2010. 